\title{
Screening for Drought-Tolerant and Low-Input Responsive Upland Rice Landraces
}

\author{
Roberto B. Barba Jr., Nicca Aira A. Marquez, Ruben P. Tablizo \\ College of Agriculture and Fisheries, Catanduanes State University, Virac, Catanduanes, Philippines \\ Email: robert barba86@yahoo.com
}

Received 20 September 2014; revised 23 October 2014; accepted 7 November 2014

Copyright (C) 2014 by authors and Scientific Research Publishing Inc.

This work is licensed under the Creative Commons Attribution International License (CC BY). http://creativecommons.org/licenses/by/4.0/

c) (†) Open Access

\begin{abstract}
Productivity potentials of upland rice landraces (URLs) are continuously compromised by scanty water supply due to competing priorities for irrigations and fluctuations in agro-ecological conditions peculiar to low-input farming systems. A growing demand for rice amidst decline in productive agricultural areas plunges into an urgent contribution of marginal areas critical in attaining food sufficiency among Filipino households. Agronomic performances of URLs locally found in Catanduanes province, Philippines were evaluated in a replicated trial utilizing three URLs: Kamanang [1], Kadari [2] and Bulaw [3]. The experimental set-up was closely monitored for consistent dry moisture content and zero fertilizer application. Results were significant for traditional upland landraces: Kamanang and Kadari, scored in terms of higher germination rate, increment plant height and the number of tillers during the vegetative stage. Leaf color gradations, although statistically not significant across cultivars, were suggestive of varying adaptive performance between traditional cultivars subjected to low-input system. Putative low-input responsive lines indicated by the higher survival percentage and overall agronomic responses were selected from the study site. Screened lines took part of the advance population which would be potentially able to tolerate poor soil conditions (i.e. poor storehouse of water and nutrients) especially in areas with edaphological constraints and changing rainfall distribution pattern. The development of putative drought tolerant lines among URLs forms the most economical solution implicated to areas with limited access to agricultural interventions.
\end{abstract}

\section{Keywords}

Upland Rice Landraces, Low-Input System, Edaphological Constraints 


\section{Introduction}

Rice (Oryza sativa) is the staple food for $90 \%$ or more Filipinos and provides about $62.5 \%$ household income for 11.5 million families [1]. It contributes $16 \%$ and $3.5 \%$ to the Gross Value Added (GVA) and the Gross Domestic Product (GDP), respectively [2]. It is not surprising that $33 \%$ of the country's agricultural lands are devoted to rice [3]. Specifically in Catanduanes, 4367 ha are devoted for upland rice farming and have produced 13717.34 MT of rice in 2012 [4].

Based on International Rice Research Institute (IRRI) report in 2009, upland rice cultivars in the Philippines range from 120 to $180 \mathrm{~cm}$ attainable height at maturity. Each plant usually has 2 to 4 productive tillers bearing large panicles with many grains per panicle ranging from 150 to 300. The duration of the vegetative phases of upland rice differs with varieties. The reproductive and ripening phases are fairly constant for most varieties. The reproductive phase lasts about 35 days; the ripening phase lasts about 30 days. The time from sowing to harvest ranges from 80 to 180 days or longer [5].

The Philippines are in "high-risk" in terms of food security basing criteria on food affordability, availability and safety. This directly implies the public health problem of the country on nutrition. Survey says 1 out of 4 Filipino children below 5 years old are underweight and stunted [6]. Whilst in a 2010 survey report among the 25 provinces in the country with long standing or chronic malnutrition, Catanduanes province had recorded $23.64 \%$ malnutrition rate affecting a very high percentage of pre-school children [7]. Upland rice farming is considered as an important initiative in attaining the goal of rice sufficiency in the region and in the country as well. Farming on an environment with 18 degrees slopes, requires less soil fertilizer application, prone to erosion and water unavailability; however it provides an opportunity to solve the household food scarcity, income and nutrition. Upland rice is widely cultivated in West Africa, Latin America and Southeast Asia especially Indonesia, Thailand, and Laos. It is well-adapted to poor environments with low-to-medium grain yields. The major problem of Upland Rice farming, however, may lodge under good management. Besides other factors, drought is the most limiting factor causing reduction in rice yield when average rainfall does not meet the water requirement by the crop [6] [8]-[10].

Upland rice farming is being threatened by climate change, ensuing an erratic intensity pattern and average rainfall. Moreover, some areas are experiencing longer dry periods whilst other regions are confronted with heavier rains [11]-[14]. The so-called El-Niño phenomenon causes significant reduction in yields of major crops including rice in Asian countries (i.e. Malaysia, Indonesia, Thailand, Philippines) in 1992 and 1997 [15]. The Philippines Atmospheric, Geophysical and Astronomical Services Administration (PAGASA) claimed possible development of El-Niño phenomenon that may begin on the last quarter of 2014 and will last up to the first quarter of 2015 [16]. This rainfall pattern is foreseen to continue, which may give crucial effects to rice farming or agricultural sector as a whole since they are largely dependent on climatic conditions in putting food secured. To reduce or endure the effect of the changing climate, development of drought resistant upland rice lines with drought tolerant is the most economical solution. Lines with drought tolerance can be identified through selection from high yielding donor lines using Drought Responsive Index (DRI) under drought stress conditions. Drought tolerance variability in upland rice lines is a well-known fact [6] [8] [9]. Moreover, high genotypic variability of rain fed and irrigated rice cultivars possessing different plant traits were also reported [17]-[21].

Locally Adapted Cultivars (LACs) or traditional Upland Rice Landraces (URLs) commonly found in resident upland rice farmers in Catanduanes were the mainstream of cultivations in the absence of improved lines or cultivars responsive to both nutrient-deficient soils and low water availability or irrigation system. Seed exchanges among neighboring farms formed part of the farmer's habit in search for new seeds to be planted for subsequent cropping season. Hence, a study was focused on screening low-input rice responsive lines among three rice cultivars which the resident farmers of Catanduanes were using to identify potential upland rice lines which would thrive well on low-input system especially during dry periods. The agronomic traits of three upland rice varieties were scored in terms of 1) date to seedling emergence, 2) plant height, 3) number of true leaves, 4) leaf color, 5) number of tillers, 6) percent survival among landraces in response to low-input system, and 7) number of potential lines across cultivars.

\section{Materials and Methods}

\subsection{Collection of Indigenous Upland Rice Landraces}

The study used three upland rice landraces (i.e. Kamanang, Kadari and Bulaw) collected within the province of 
Catanduanes, Philippines (Table 1). Pertinent features like local name and maturity of each cultivar were indicated based on the first hand information given by the farmers from whom the seeds were collected. Landraces derived from on-field collections were the mainstream of cultivations the farmers had been using through years in nearly remote barangays of Catanduanes, Philippines.

\subsection{Experimental Design, Seedling Establishment and Field Layout}

The study was conducted at the College of Agriculture and Fisheries Crop Experiment Station (CAF-CES), Catanduanes State University through pot experiment following a Completely Randomized Design (CRD) for three Upland Rice Landraces subjected to low-input culture with maintained dry moisture content, $7.0 \mathrm{pH}$ level, high density planting and with zero fertilizer application. Qualitative moisture content (i.e. dry, moist or wet) was determined using soil moisture tester (4 in 1 Soil Survey Instrument). Calibration and critical monitoring for dry moisture content of the low-input set-up was facilitated through the use of sandy:stony $(1: 1 \mathrm{v} / \mathrm{v})$ modified growing medium, categorically known to be droughty, hence, a poor storehouse for both water and nutrients (Figure 1).

\subsection{Data Collection}

The agronomic traits were periodically measured at the vegetative stage covering specific stages from rice emergence to early tillering stage of each cultivar for about 42 days. Data collected include the following parameters: periodic germination percentage, number of tillers, plant height $(\mathrm{cm})$, number of true leaves, green color gradient/score, percentage survival and number of potential low-input rice responsive lines across landraces.

\subsection{Data Analysis}

All data were analyzed using one-way analysis of variance (ANOVA) technique, by using SPSS 17.0 software to determine the degree of significance between treatments. Mean separation among significant treatments was

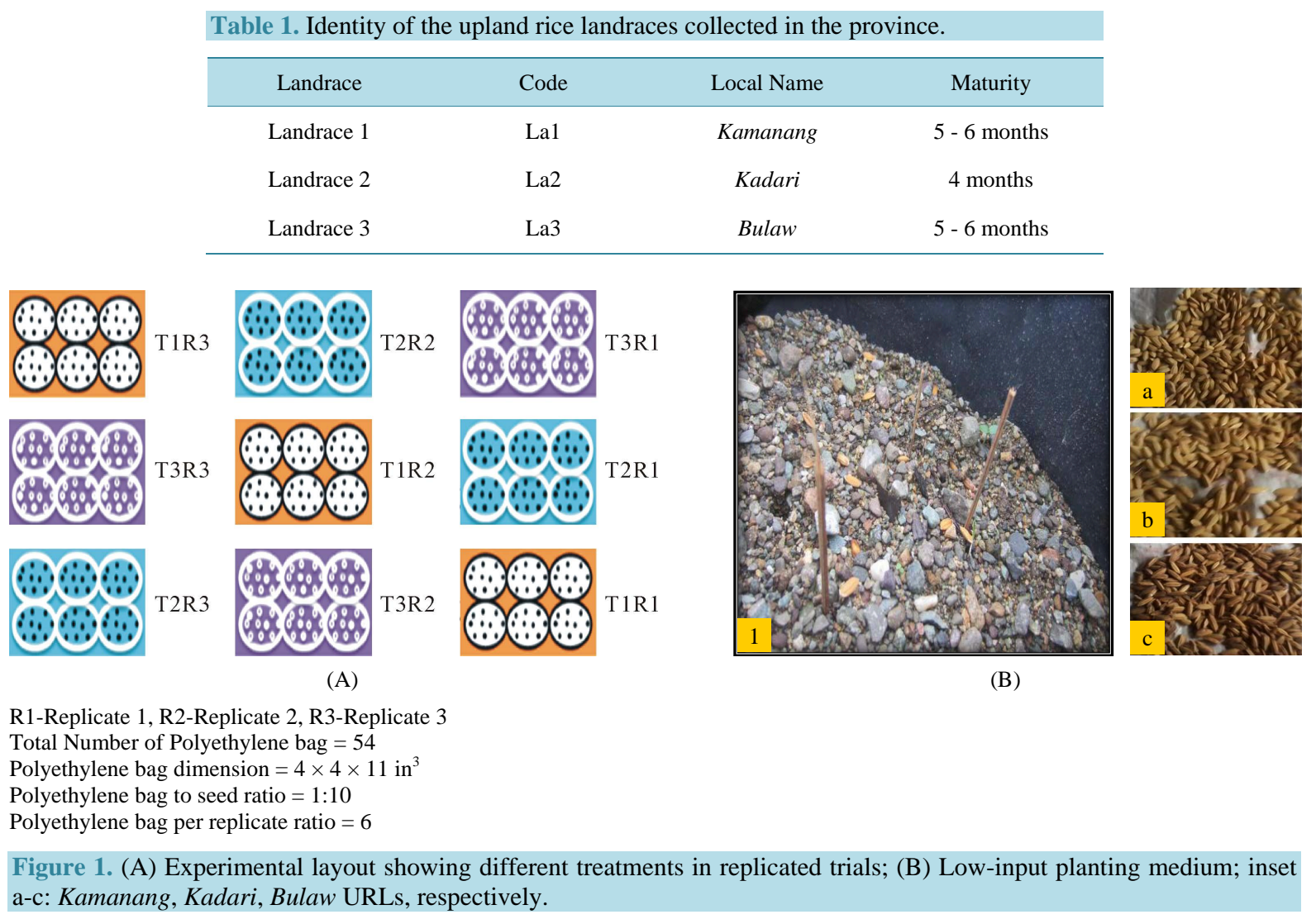

Figure 1. (A) Experimental layout showing different treatments in replicated trials; (B) Low-input planting medium; inset a-c: Kamanang, Kadari, Bulaw URLs, respectively. 
done using LSD pairwise comparison (i.e. $\mathrm{p} \leq 0.05$ ).

\section{Result and Discussion}

\subsection{Date to Seedling Emergence of Upland Rice Landraces}

The analysis of variance (ANOVA) test for percent germination of three upland rice landraces observed from first to eighth Day After Sowing (DAS) had revealed significance among treatments. Mean analysis indicates that in terms of percent germination, "Kamanang" and "Kadari" landraces have significantly the same germination percentage compared to "Bulaw" landrace which shows consistently least percent germination throughout the $8^{\text {th }}$ day observation period. Variations in germination percentage could be the effect of environmental stressors (i.e. temperature etc.) [22] (Table 2).

\subsection{Plant Height}

In terms of plant height, the result showed significant differences between treatments at $p \leq 0.05$. Summary of statistical results through $6^{\text {th }}$ weeks observation period is presented on Table 3 . The results revealed that "Kamanang" and "Kadari" landraces obtained comparative increment in plant height on a weekly basis relative to "Bulaw" landrace. The fluctuating mean, however, from the $3^{\text {rd }}$ to the last observation period of "Kadari" landrace might be implicated to staggered seedling death while the "Bulaw" landrace obtained least survival of seedlings and accumulated the lowest average plant height when subjected to low-input system.

\subsection{Average Number of True Leaves}

In terms of the number of true leaves, "Kamanang" and "Kadari" cultivars exhibited similar performance on the initial weeks (i.e. $2^{\text {nd }}$ to $3^{\text {rd }}$ weeks) of the observation period than "Bulaw" cultivar. However, "Kamanang" cultivar had shown consistently highest number of synthesized true-leaves during vegetative stage. The results underscore the significant adaptation of "Kamanang" cultivar for leaf formation relative to intermediate adaptation of "Kadari" cultivar and the sensitivity of "Bulaw" cultivar to drought and nutrient deficiencies (Table 4).

\subsection{Leaf Color Score}

In terms of the green color gradation, all treatments (i.e. upland rice landraces) have statistically the same color gradient score which was measured using a standard leaf color chart [23] from $3^{\text {rd }}$ week to $6^{\text {th }}$ week duration.

Table 2. Germination percentage (\%) of three upland rice landraces from $1^{\text {st }}$ to $8^{\text {th }}$ day of the observation period.

\begin{tabular}{|c|c|c|c|c|c|c|c|c|}
\hline \multirow{2}{*}{ Landrace } & \multicolumn{8}{|c|}{ Germination Percentage* } \\
\hline & Day 1 & Day 2 & Day 3 & Day 4 & Day 5 & Day 6 & Day 7 & Day 8 \\
\hline Kamanang & 0 & 0 & $100^{\mathrm{A}}$ & $100^{\mathrm{A}}$ & $100^{\mathrm{A}}$ & $100^{\mathrm{A}}$ & $100^{\mathrm{A}}$ & $100^{\mathrm{A}}$ \\
\hline Kadari & 0 & 0 & $91.67^{\mathrm{A}}$ & $96.11^{\mathrm{A}}$ & $100^{\mathrm{A}}$ & $100^{\mathrm{A}}$ & $100^{\mathrm{A}}$ & $100^{\mathrm{A}}$ \\
\hline Bulaw & 0 & 0 & $0.56^{\mathrm{B}}$ & $3.33^{\mathrm{B}}$ & $3.38^{\mathrm{B}}$ & $9.44^{\mathrm{B}}$ & $13.3^{\mathrm{B}}$ & $20^{\mathrm{B}}$ \\
\hline
\end{tabular}

*Mean(s) in a column having similar letter(s) is/are not significant at $\mathrm{p} \leq 0.05$ level of significance.

Table 3. Average weekly increment in plant height (cm).

\begin{tabular}{|c|c|c|c|c|c|}
\hline \multirow{2}{*}{ Landrace } & \multicolumn{5}{|c|}{ Germination Percentage ${ }^{*}$} \\
\hline & Week 2 & Week 3 & Week 4 & Week 5 & Week 6 \\
\hline Kamanang & $12.89^{\mathrm{A}}$ & $15.45^{\mathrm{A}}$ & $19.17^{\mathrm{A}}$ & $18.39^{\mathrm{A}}$ & $19.67^{\mathrm{A}}$ \\
\hline Kadari & $11.83^{\mathrm{A}}$ & $12.95^{\mathrm{A}}$ & $11.33^{\mathrm{A}}$ & $10.78^{\mathrm{A}}$ & $11^{\mathrm{A}}$ \\
\hline Bulaw & $0.67^{\mathrm{B}}$ & $0.67^{\mathrm{B}}$ & $0.5^{\mathrm{B}}$ & $0.67^{\mathrm{B}}$ & $0.83^{\mathrm{B}}$ \\
\hline
\end{tabular}

${ }^{*}$ Mean(s) in a column having similar letter(s) is/are not significant at $\mathrm{p} \leq 0.05$ level of significance. 
The green color gradient score of the three rice landraces from $3^{\text {rd }}$ to $6^{\text {th }}$ week's observation is shown on Figure 2. Though the mean score across treatments and periods revealed no significant difference, it is numerically noteworthy to consider the differing adaptive behaviour of the three rice landraces grown under restricted medium. The "Kamanang" landrace observed quiescent performance in leaf color synthesis for atmost a month duration but surprisingly obtained significant scores for the $5^{\text {th }}$ and $6^{\text {th }}$ weeks periods; the "Kadari" cultivar had shown consistent average (i.e. LCC score $=2$ ) throughout. The seemingly adaptive and responsive strategy indicated by increasing scores of the "Bulaw" landrace (LCC values usually higher than 2) may possibly indicate an exhaustive mechanism of this landrace as there had been recorded low percent germination, hence, lesser seedlings mean greater access to resources than do close density planting.

\subsection{Tillering Ability of Rice Cultivars}

The onset of active tiller formation for these upland rice landrace was observed at the $5^{\text {th }}$ week observation and persisted until $6^{\text {th }}$ week. The tillering ability on the $5^{\text {th }}$ week delineated no significant difference among landraces. The "Kamanang" landrace, however, had shown a remarkable increase in number of tillers even subjected under prolonged low-input system (i.e. presence of low soil moisture content, poor nutrient and high density planting). On the other hand, treatment 3 "Bulaw" landrace showed no response in number of tillers grown in a restricted medium (Table 5).

Table 4. Average number of true leaves of three rice cultivars from the $2^{\text {nd }}$ to $6^{\text {th }}$ week of the observation period.

\begin{tabular}{|c|c|c|c|c|c|}
\hline \multirow{2}{*}{ Landrace } & \multicolumn{5}{|c|}{ Germination Percentage ${ }^{*}$} \\
\hline & Week 2 & Week 3 & Week 4 & Week 5 & Week 6 \\
\hline Kamanang & $1.6^{\mathrm{A}}$ & $1.55^{\mathrm{A}}$ & $1.92^{\mathrm{A}}$ & $1.84^{\mathrm{A}}$ & $1.9^{\mathrm{A}}$ \\
\hline Kadari & $1.24^{\mathrm{A}}$ & $1.30^{\mathrm{A}}$ & $1.13^{\mathrm{B}}$ & $1.08^{\mathrm{B}}$ & $1.08^{\mathrm{B}}$ \\
\hline Bulaw & $0.07^{\mathrm{B}}$ & $0.07^{\mathrm{B}}$ & $0.63^{\mathrm{C}}$ & $0.07^{\mathrm{C}}$ & $0.08^{\mathrm{C}}$ \\
\hline
\end{tabular}

${ }^{*}$ Mean(s) in a column having similar letter(s) is/are not significant at $\mathrm{p} \leq 0.05$ level of significance.

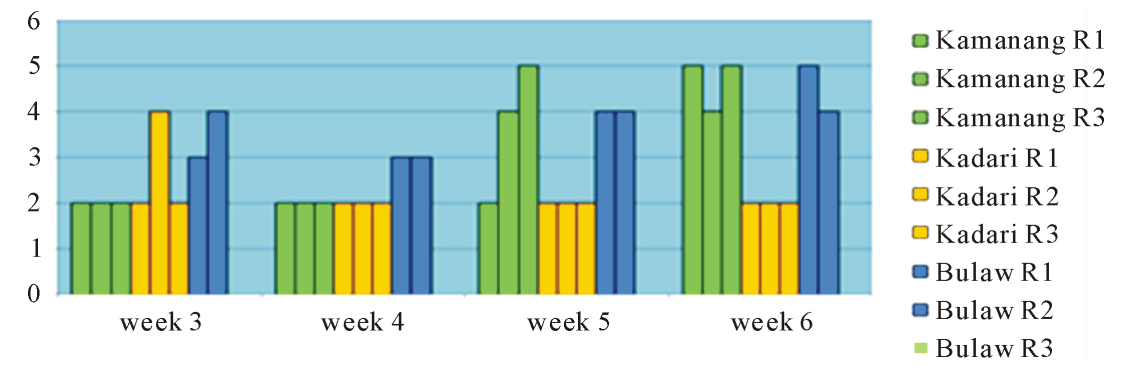

Figure 2. Green color gradient score of the three rice cultivars per replicate from the $2^{\text {nd }}$ to $6^{\text {th }}$ week of the observation period.

Table 5. Number of tillers of three rice landraces from the $3^{\text {rd }}$ to $6^{\text {th }}$ week of the observation period.

\begin{tabular}{ccc}
\hline \multirow{2}{*}{ Landrace } & \multicolumn{2}{c}{ Germination Percentage $^{*}$} \\
\cline { 2 - 3 } & Week 5 & Week 6 \\
\hline Kamanang & $0.78^{\mathrm{A}}$ & $1.61^{\mathrm{A}}$ \\
Kadari & $0.14^{\mathrm{A}}$ & $0.7^{\mathrm{B}}$ \\
Bulaw & $0^{\mathrm{A}}$ & $0^{\mathrm{B}}$ \\
\hline
\end{tabular}

${ }^{*}$ Mean(s) in a column having similar letter(s) is/are not significant at $\mathrm{p} \leq 0.05$ level of significance. 


\subsection{Periodic Survival Percentage in a Modified Low-Input System}

Two landraces (i.e. "Kamanang” and "Kadari”) were significant than "Bulaw" landrace but followed a general decline in survival percentage of seedlings based on the weekly observations. There had been greater count of seedlings observed from the two significant treatments (i.e. Kamanang and Kadari landrace) relative to the low adaptability of "Bulaw" seedlings in the study site (Table 6).

\subsection{Number of Low-Input Responsive Lines across Cultivars}

The three upland rice landraces derived from on-field collections had shown two degree of response to poor soil type. "Kamanang" and "Kadari" landraces exhibited significant number of potential lines selected than "Bulaw" landrace based on the test conducted. Results might be implicated to the population structure of each landrace which existed through years of cultivation under farmer's field; "Bulaw" landrace reflected a nearly homogenous population structure that offers higher sensibility to nutrient and water limitations. Conversely, "Kamanang" and "Kadari" landraces suggested relatively mixed/heterogenous population structure that offers variability for adaptive trait(s) being considered. The higher number of potential lines selected can be well correlated to the low-input adaptability of the two cultivars observed in the study (Table 7).

\subsection{Agronomic Performances of Upland Rice Landraces}

Since water stresses affects plant germination, selection of survival among the fittest genotypes has been employed to identify potential drought-tolerant/resistant lines [24]-[28]. Kamanang and Kadari upland rice landraces (URLs) expressed remarkable germination rate with the onset of complete (100\%) germination percentage on the $3^{\text {rd }}$ and $5^{\text {th }}$ Days After Sowing (DAS), respectively. When water is limited, rice cycle was prolonged; plant height was reduced [29]. In the current study, the maximum height reached by Kamanang ${ }^{1}$ landrace (i.e. statistically similar to Kadari upland landrace) was approximately $20 \mathrm{~cm}$ (by which other author posed that it may reach up to $30 \mathrm{~cm}$ on the late vegetative stage [30]), however plant height may differ with respect to genotypes. Also significant differences in terms of number of leaves between the three landraces were recorded. $\mathrm{Ka}$ manang and Kadari landraces have the highest number of leaves. This may be an indication that these lines have adaptive expressions on drought and low nutrient soil condition relative to Bulaw landrace' consistently poor performance under a modified sandy:stony $(1: 1 \mathrm{v} / \mathrm{v})$ growing medium. Nitrogen which constitutes the green leaf color of the leaves is the most limiting plant nutrient element where it is the main driver of plant growth and

Table 6. Weekly survival percentage of three rice cultivars.

\begin{tabular}{cccccc}
\multirow{2}{*}{ Landrace } & \multicolumn{3}{c}{ Germination Percentage $^{*}$} \\
\cline { 2 - 5 } & Week 2 & Week 3 & Week 4 & Week 5 & Week 6 \\
\hline Kamanang & $59.44^{\mathrm{A}}$ & $57.22^{\mathrm{A}}$ & $56.66^{\mathrm{A}}$ & $46.11^{\mathrm{A}}$ & $44.43^{\mathrm{A}}$ \\
Kadari & $58.33^{\mathrm{A}}$ & $55^{\mathrm{A}}$ & $45.55^{\mathrm{A}}$ & $33.89^{\mathrm{A}}$ & $32.22^{\mathrm{A}}$ \\
Bulaw & $19.98^{\mathrm{B}}$ & $19.98^{\mathrm{B}}$ & $19.98^{\mathrm{B}}$ & $19.98^{\mathrm{B}}$ & $19.98^{\mathrm{B}}$ \\
\hline
\end{tabular}

*Mean(s) in a column having similar letter(s) is/are not significant at $\mathrm{p} \leq 0.05$ level of significance.

Table 7. Number of screened lines from three rice landraces responsive to low-input system.

\begin{tabular}{cc}
\hline Landrace & Number of Screened Lines $^{*}$ \\
\hline Kamanang & $35^{\mathrm{A}}$ \\
Kadari & $25^{\mathrm{A}}$ \\
Bulaw & $2^{\mathrm{B}}$ \\
\hline
\end{tabular}

${ }^{*}$ Mean(s) in a column having similar letter(s) is/are not significant at $\mathrm{p} \leq 0.05$ level of significance.

${ }^{1}$ Screening for drought-tolerant and low-input responsive upland rice landraces. 
yield [31]. However there were no significant differences between the three landraces in terms of leaf color gradient (below $=$ score 2). Cultivars exhibited a low nitrogen assimilation implicated by the low nutrient availability and the ease with which nutrients are present under dry soil moisture content of the medium. Water deficit also reduces rice tillering ability [32]. In the study tillers appeared on the $5^{\text {th }}$ and $6^{\text {th }}$ week observation period [31]. At the end of the six week observation period (i.e. seedling to early tillering stage) survival percentage of the three landraces subjected to the dry and low-nutrient soil media was recorded. Kamanang and Kadari landrace exhibited significant number of survived lines. The study is in accordance with the findings of other authors proving variations in different plant traits (i.e. drought tolerant lines) [6] [8] [9] [17]-[21]. Drought-tolerant trait might be recognized as the most important trait to be improved in rice [15]. Screened lines as delineated by its agronomic performances were potential selections with drought tolerance character crucial for optimal yield among upland rice landraces.

\section{Conclusion}

Putative selections from Kamanang and Kadari upland rice landraces exhibited agronomic behaviors that responded positively under low-input culture system. Variability for the agronomic traits suggests population structure of traditional landraces fortuitously mixed-up through subsequent cropping cycles. Advanced selections of drought-responsive lines prelude URLs development in specific breeding program relative to agro-climatic fluctuations.

\section{Acknowledgements}

The researchers would like to express gratitude for the funding support extended by the Department of Agriculture as per approved program on Catanduanes Indigenous Rice Development (CIRDEP) of the Catanduanes State University Virac, Catanduanes.

\section{References}

[1] David, C.C. and Balisacan, A. (1995) Philippine Rice Supply Demand: Prospects and Policy Implications. Philippine Institute of Development Studies, Makati City.

[2] Gonzales, L.A. (1999) The Global Rice Industry. Philippine Technical Bulletin, 4, PhilRice Maligaya, Muñoz, Nueva Ecija.

[3] John J. Carroll Institute on Church and Social Issues (2009) Small Rice Farmers' Adaptation to Climate Change in the Philippines Final Manuscript.

[4] Provincial Agriculture Services Office, Province of Catanduanes. http://catanduanes.gov.ph/paso/

[5] International Rice Research Institute (2009) Rice Knowledge Bank. Farmer's Guide to Upland Rice Growing. http://www.knowledgebank.irri.org/extension/farmersguideuplandrice.html.2009

[6] Heinemann, A.B. and Stone, L.F. (2009) Efeito da deficiênciahídrica no desenvolvimento e rendimento de quatrocultivares de arroz de terrasaltas. Pesquisa Agropecuária Tropical, 39, 134-139.

[7] DSWD Allocates P8M Fund for Supplemental Feeding in Catanduanes (2011). http://balita.ph/2011/07/25/dswd-allocates-p8m-fund-for-supplemental-feeding-in-catanduanes/

[8] Cabuslay, G.S., Ito, O. and Alejar, A.A. (2002) Physiological Evaluation of Responses of Rice (Oryzasativa L.) to Water Deficit. Plant Science, 163, 815-827. http://dx.doi.org/10.1016/S0168-9452(02)00217-0

[9] Lafitte, H.R. and Bennett, J. (2002) Requirements for Aerobic Rice: Physiological and Molecular Considerations. In: Bouman, B.A.M., Hengsdijk, H., Hardy, B., Bindraban, P.S., Tuong, T.P. and Ladha, J.K., Eds., Water-Wise Rice Production, International Rice Research Institute, Los Baños, 259-274.

[10] Oak, M.B., Tsubo, J., Fukai, M., Fisher, S., Cooper, K.S. and Nesbitt, M. (2006) Use of Drought Response Index for Identification of Drought Tolerant Genotypes in Rainfed Lowland Rice. Crop Science Research, 99, 48-58. http://dx.doi.org/10.1016/j.fcr.2006.03.003

[11] Allen, R.J. (1988) El Niño-Southern Oscillation Influences in the Australasian Region. Progress in Physical Geography, 12, 313-348. http://dx.doi.org/10.1177/030913338801200301

[12] John, J. (2009) Small Rice Farmers’ Adaptation to Climate Change in the Philippines. Final Manuscript, Carroll Institute on Church and Social Issues.

[13] Diaz, H.F. and Kiladis, G.N. (1995) Climatic Variability on Decadal to Century Time Scales. In: Henderson-Sellers, R., Ed., World Survey of Climatology Vol. 16, Future Climates of the World: A Modelling Perspective, Elsevier, Amster- 
dam, 191-244.

[14] Nichols, N. (1993) ENSO, Drought and Flooding Rain in Southeast Asia. In: Brookfiled, H. and Bryons, Y., Eds., Southeast Asia's Environmental Future: The Search for Sustainability, Oxford University Press, Melbourne, 154-175.

[15] Fukai, S. and Cooper, M. (1995) Development of Drought-Resistant Cultivars Using Physio-Morphological Traits in Rice. Field Crops Research, 40, 67-86. http://dx.doi.org/10.1016/0378-4290(94)00096-U

[16] O’Toole, J.C. (2004) Rice and Water: The Final Frontier. Proceedings of the First International Conference on Rice for the Future, Bangkok, 31 August-2 September 2004, 26.

[17] Akram, M., Rehman, A., Ahmadand, M. and Cheema, A.A. (2007) Evaluation of Rice Hybrids for Yield and Yield Components in Three Different Environments. Journal of Animal and Plant Sciences, 17, 70-75.

[18] Miyagawa, S. and Kuroda, T. (1988) Variability of Yield and Yield Components of Rice in Rain-Fed Paddy Fields of Northeast Thailand. Japanese Journal of Crop Science, 57, 527-534. http://dx.doi.org/10.1626/jcs.57.527

[19] Pantuwan, G., Fukai, S., Cooper, M., Rajatasereekul, S. and Toole, J.C.O. (2002) Yield Response of Rice (Oryzasativa L.) Genotypes to Different Types of Drought under Rainfed Lowlands: Part 1. Grain Yield and Yield Components. Field Crops Research, 73, 153-168. http://dx.doi.org/10.1016/S0378-4290(01)00187-3

[20] Zhang, Y., Tang, Q., Zou, Y., Li, D., Qin, J., Yang, S., Chen, L., Xia, B. and Peng, S. (2009) Yield Potential and Radiation Use Efficiency of “Super” Hybrid Rice Grown under Subtropical Conditions. Field Crops Research, 114, 91-98. http://dx.doi.org/10.1016/j.fcr.2009.07.008

[21] Zhou, G.S., Jin, D.M. and Mei, F.Z. (2007) Effect of Drought on Rice Grain Indices at Booting Stage. Journal of Huazhong Agricultural University, 3, 219-222.

[22] McDonald, M.B. and Copeland, L. (1997) Seed Production: Principles and Practices. Chapman and Hall, New York, 249 p. http://dx.doi.org/10.1007/978-1-4615-4074-8

[23] Global Food Security Index.

[24] Li, X.P., Tian, A.G., Luo, G.Z., Zhang, J.S. and Chen, S.Y. (2005) Soybean DRE-Binding Transcription Factors That Are Responsive to Abiotic Stresses. Theoretical and Applied Genetics, 110, 1355-1362. http://dx.doi.org/10.1007/s00122-004-1867-6

[25] Kaboli, M. and Sadeghi, M. (2002) Effect of Water Stress on Germination in Three Species of Onobrychis. Watershed Management Researches, 15, 18-21.

[26] Hassanpanah, D. (2009) In Vitro and in Vivo Screening of Potato Cultivars against Water Stress by Polyethylene Glycol and Potassium Humate. Biotechnology, 8, 132-137. http://dx.doi.org/10.3923/biotech.2009.132.137

[27] Nasirzadeh, A. and Shookoh, M.K. (2006) Physiological Effects of Drought on Germination and Seedling Elongation in Onobrychis Species. Iranian Journal of Rangelands and Forests Plant Breeding and Genetic Research, 11, e465e478.

[28] Bermingham, E.N., Hutchinson, K.J., Revell, D.K., Brookes, I.M. and McNabb, W.C. (2006) The Effect of Condensed Tannins in Sainfoin (Onobrychis viciifolia) and Sulla (Hedysarum coronarium) on the Digestion of Amino Acids in Sheep. New Zealand Society of Animal Production, New Zealand.

[29] Arf, O., Rodrigues, R.A.F., de Sá, M.E. and Crusciol, C.A.C. (2001) Resposta de cultivares de arroz de sequeiroaopreparo do solo e à irrigaçãoporaspersão. Pesquisa Agropecuária Brasileira, 36, 871-879. http://dx.doi.org/10.1590/S0100-204X2001000600004

[30] Nutritional Recommendation for Rice. Pioneering the Future, Haifa.

[31] Tilman, D. (1999) Global Environmental Impacts of Agricultural Expansion: The Need for Sustainable and Efficient Practices. Proceedings of the National Academy of Sciences of the United States of America, 96, 5995-6000. http://dx.doi.org/10.1073/pnas.96.11.5995

[32] Fornasieri Filho, D. and Fornasieri, J.L. (1993) Manual da cultura de arroz. Funep, Jaboticabal, 221 p. 
Scientific Research Publishing (SCIRP) is one of the largest Open Access journal publishers. It is currently publishing more than 200 open access, online, peer-reviewed journals covering a wide range of academic disciplines. SCIRP serves the worldwide academic communities and contributes to the progress and application of science with its publication.

Other selected journals from SCIRP are listed as below. Submit your manuscript to us via either submit@scirp.org or Online Submission Portal.
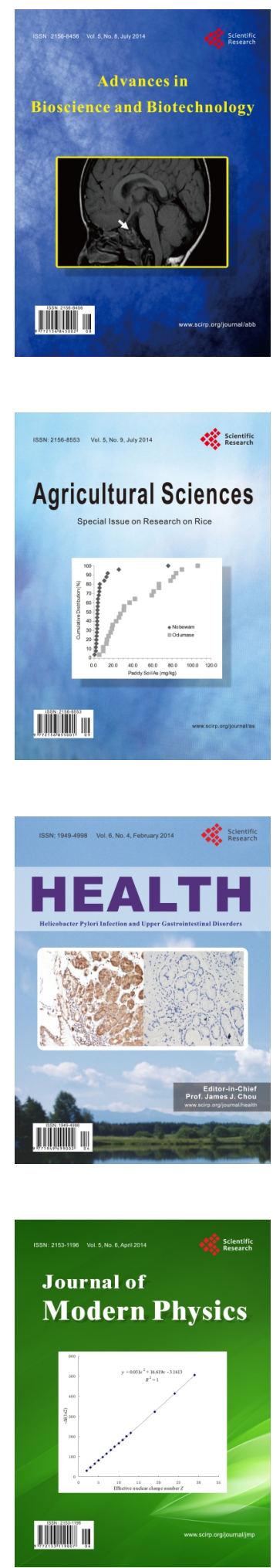
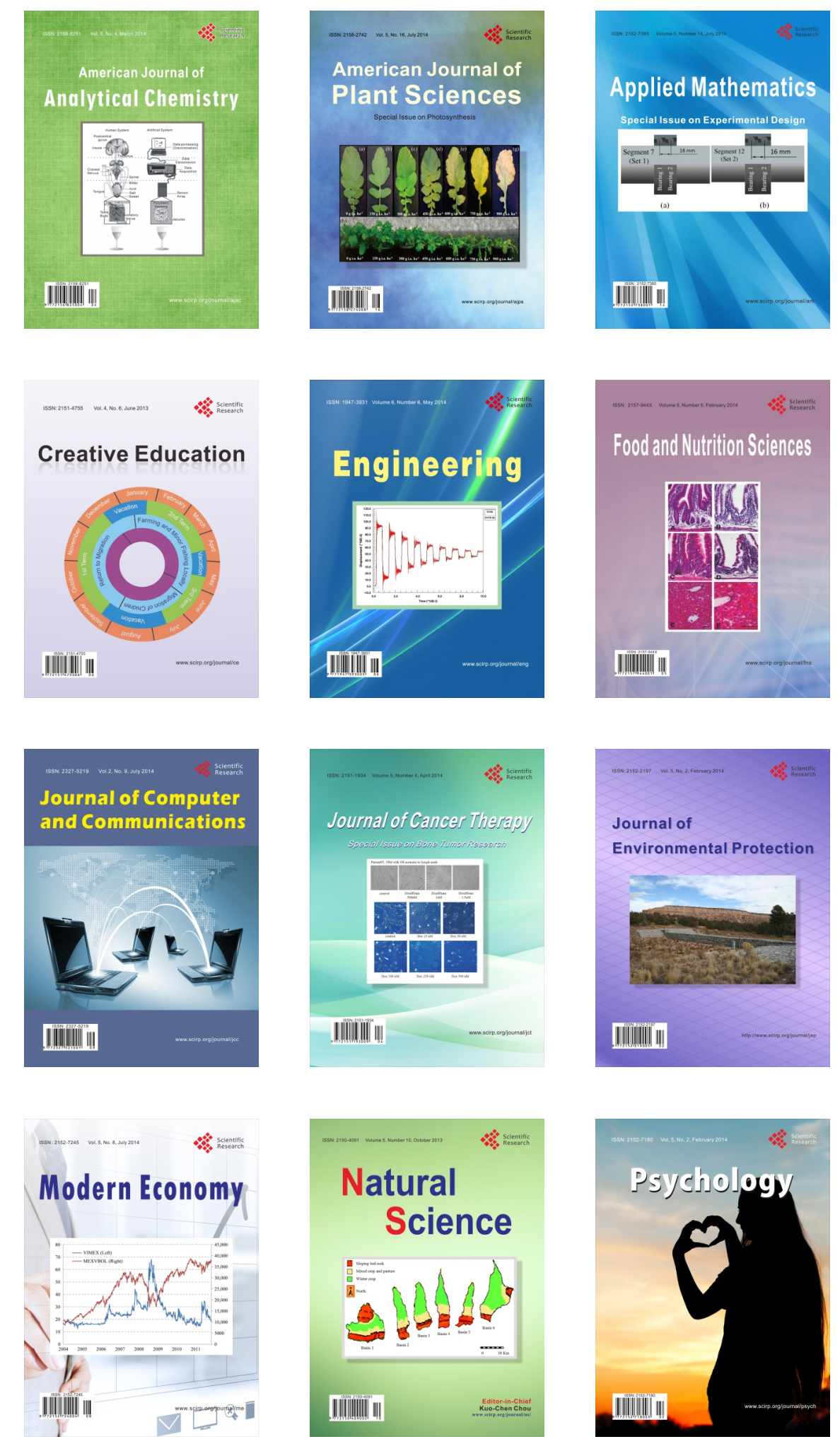